\title{
A Recessive Mutation in Rice Conferring Non-Race-Specific Resistance to Bacterial Blight and Blast
}

\author{
Ma. Reina Suzette Madamba • Nobuko Sugiyama • Alicia Bordeos • Ramil Mauleon • \\ Kouji Satoh • Marietta Baraoidan • Shoshi Kikuchi $\cdot$ Ko Shimamoto $\cdot$ Hei Leung
}

Received: 17 April 2009 / Accepted: 8 June 2009 /Published online: 26 June 2009

(C) Springer Science + Business Media, LLC 2009

\begin{abstract}
To understand the basis of broad-spectrum disease resistance in rice, we isolated a gamma-rayinduced IR64 mutant G978 that showed enhanced resistance to blast and bacterial blight. The resistance is quantitative and non-race specific against the bacterial and fungal pathogens. The mutation is inherited as a single recessive gene, designated as $B s d r 1$ and causes shorter stature relative to the wild type; however, it does not show lesion mimics phenotype under the conditions tested. The mutation was mapped as a quantitative trait locus to a 3.8$\mathrm{Mb}$ region on chromosome 12. By comparing the gene expression profiles of the mutant and wild type, we identified a candidate gene encoding a U-box domaincontaining protein. The disrupted gene showed a loss of expression in the mutant and co-segregated with mutant
\end{abstract}

Ma. Reina Suzette Madamba, Nobuko Sugiyama, Alicia Bordeos contributed equally to this work.

Electronic supplementary material The online version of this article (doi:10.1007/s12284-009-9027-x) contains supplementary material, which is available to authorized users.

M. R. S. Madamba $\cdot$ N. Sugiyama $\cdot$ A. Bordeos $\cdot$ R. Mauleon $\cdot$

M. Baraoidan $\cdot H$. Leung $(\square)$

Division of Plant Breeding, Genetics and Biotechnology,

International Rice Research Institute,

DAPO 7777 Metro Manila, Philippines

e-mail: h.leung@cgiar.org

K. Satoh $\cdot$ S. Kikuchi

Unit of Plant Genome Research,

National Institute of Agrobiological Sciences,

Tsukuba, Japan

K. Shimamoto

Laboratory of Plant Molecular Genetics,

Nara Institute of Science and Technology,

8916-5 Takayama,

Ikoma 630-0101, Japan phenotype. The mutant provides a useful tool for investigating the important genes responsible for non-race specific resistance to two distinct diseases.

Keywords Broad-spectrum disease resistance - Gamma-ray mutagenesis · Gene expression profiling · IR64 ·

QTL mapping

\section{Introduction}

Major resistance (R) genes have been used for disease control in many crops to provide resistance to specific pathogens. The $\mathrm{R}$ gene-mediated defenses typically involve a rapid, localized cell death, or hypersensitive response (HR), and formation of antimicrobial chemicals that restrict pathogen invasion at the site of infection (Hammond-Kosack and Jones 1996; Keen 1990; Martin 1999). Some of these genes, however, lose effectiveness rapidly in cases where the pathogens are capable of evading the recognition by changing the corresponding effector (also called avirulence or Avr) genes. This has prompted an increasing interest in host defense genes which are not directly involved in the recognition of specific strains of pathogens. These defenseresponse (DR) genes are implicated to contribute to quantitative and broad-spectrum resistance to pathogens (Faris et al. 1999; Freialdenhoven et al. 1996; Liu et al. 2004; Lu et al. 2004; Ramalingam et al. 2003; Wen et al. 2003). Broad-spectrum disease resistance is desirable because of its potential for conferring durable resistance against diverse races of a pathogen or multiple pathogens.

Mutational analysis provides an effective means for identifying genes involved in different stages or components of resistance expressed by a plant. Mutants with altered response to pathogens, either gain or loss of 
resistance, are particularly useful for dissecting defense mechanisms. In the case of gain-of-resistance mutants, several studies have provided useful insights into the regulation of defense (Feys and Parker 2000; Frye and Innes 1998; Yu et al. 2000; Thatcher et al. 2005). In Arabidopsis thaliana, a recessive mutant edrl (enhanced $d$ isease resistance 1) presents a high level of resistance to some bacterial and fungal pathogens (Frye and Innes 1998). EDR1 encodes a raf-like mitogen-activated protein kinase kinase kinase that may function as a negative regulator of disease resistance (Frye et al. 2001). The recessive mlo mutation in barley confers broad-spectrum resistance to diverse isolates of the fungus Blumeria graminis $\mathrm{f}$. $\mathrm{sp}$. hordei. The Mlo gene encodes a novel class of plantspecific integral membrane proteins anchored in the plasma membrane by seven transmembrane domains (Buschges et al. 1997; Devoto et al. 1999, 2003a). Mlo is found to be a negative regulator of defense-responses and/or cell death such that the null mlo alleles mediate resistance by allowing an elevated level of defense responses to occur constitutively during infection by pathogen, a function that is dependent on Rorl and Ror 2 (required for mlo-specified resistance)(Anderson et al. 2005; Peterhansel et al. 1997).

In rice, bacterial blight (BB; caused by Xanthomonas oryzae pv. oryzae, Хoo) and blast (caused by Magnaporthe oryzae) are the most important diseases worldwide and they also serve as model systems for investigations of plantpathogen interactions in monocots. Rice mutants with altered response to diseases have been found (Campbell and Ronald 2005; Wang et al. 2004). Lesion mimic (LM) mutants showing broad-spectrum resistance to blast or bacterial blight have been identified (Arase et al. 2000; Mizobuchi et al. 2002; Takahashi et al. 1999; Wu et al. 2008; Yin et al. 2000; Zeng et al. 2002). These mutants develop spontaneous lesions that resemble disease symptoms in the absence of pathogen attack, some of which have been shown to be involved in programmed cell death, leading to enhanced disease resistance to multiple pathogens. For example, the spl11 (spotted leaf) mutant confers non-racespecific resistance to blast and bacterial blight and the level of resistance in this mutant correlates with the defenserelated gene expression and lesion development on the leaves (Yin et al. 2000). Zeng et al. (2004) showed that Spl11 encodes an E3 ubiquitin ligase which functions as a negative regulator of cell death and defense through its role in protein quality control. Campbell and Ronald (2005) screened a fastneutron mutagenized rice (var. CO39) population and identified three mutants-ebr1, ebr2, and ebr3 (enhanced $b$ last resistance) that display enhanced resistance to $M$. oryzae. Both ebrl and ebr3 also confer enhanced resistance to the BB pathogen. ebr3 has an LM phenotype upon inoculation with M. oryzae and Xoo and the phenotype is also induced by a shift in environmental conditions.
In this study, we investigated the phenotypic characteristics and genetic control of a gain-of-resistance mutant of IR64, a widely grown indica rice variety. This mutant, G978, showed broad-spectrum resistance to BB and blast but did not exhibit LM under normal greenhouse conditions. We characterized the level of resistance of this mutant by artificial inoculation and by field evaluation at both vegetative and reproductive stages. Genetic analyses showed that the mutation is controlled by a recessive gene. By genotyping the phenotypic extremes of a recombinant population, we mapped the G978 mutation onto a short segment on chromosome 12. Whole-genome gene expression analysis of the mutant revealed 12 down-regulated genes within the mapped interval. Gene expression and cosegregation analysis further delimit the region, leading to identification of a candidate gene that co-segregated with the gain-of-resistance phenotype. The genetically and phenotypically defined mutant provides a vehicle for investigating the important genes responsible for non-racespecific resistance to two distinct diseases.

\section{Results}

G978-18 exhibited non-race specific resistance to the bacterial blight and blast pathogens

To determine its BB resistance spectra, the gain-ofresistance IR64 mutant G978-18, isolated from a screen using Philippine Xoo strain PXO87, was tested against representative strains of the ten Xoo races from the Philippines. The two G978-18 sister lines showed highly enhanced resistance to all ten Xoo races, comparable to that conferred by major $\mathrm{R}$ genes (Fig. 1a and $\mathrm{b}$ ). The resistant mutants had mean lesion lengths ranging from 0.56 $5.41 \mathrm{~cm}$ which were five to ten times shorter than those in the susceptible sister line G978-12 and IR64. Even though IR64 is incompatible to six Xoo races (races 1, 5, 7, 8 , 9, and 10), the two G978-18 sister lines still had shorter lesions compared to the wild type (Fig. 1a).

G978-18 also showed partially enhanced resistance to blast when inoculated with IR64-compatible blast isolates PO6-6 and Ca89 at seedling stage (Fig. 1c, Table 1). G978-18 showed significant reductions in mean lesion density and percent diseased leaf area (\% DLA) at low and high-inoculum concentrations ( 25 and $75 \times 10^{4}$ spores $/ \mathrm{ml}$ ) compared to the susceptible sister line G978-12-16 and IR64 (data for $75 \times 10^{4}$ spores $/ \mathrm{ml}$ shown in Table 1). Consistent with the results of greenhouse inoculations, G978-18 exhibited enhanced resistance under natural infection in the blast nursery. In two independent tests, the two G978-18 sister lines showed less disease, measured as \% DLA at five time points up to 26 days after sowing, than IR64 or G978-12-16 (Fig. 2). 
Fig. 1 Enhanced resistance to bacterial blight and blast in IR64 mutant G978-18. a Resistant lines G978-18-8 and G978-1816 compared with susceptible sister line G978-12-16 and IR64 (wild type) in inoculation tests against ten races of Xanthomonas oryzae pv. oryzae (Xoo) from the Philippines. Lesion length represents mean values of three replications. $R$ resistant, $S$ susceptible. Error bars indicate \pm SE. b Disease reaction of G978-18-8, G978-12-16, and IR64 to Xoo strain PXO87 (race 3 ) and $\mathbf{c}$ enhanced resistance to blast isolate, Ca89 in G978-188 compared to wild-type IR64. CO39 is a susceptible check.

\section{a}

Lesion length $(\mathrm{cm})$

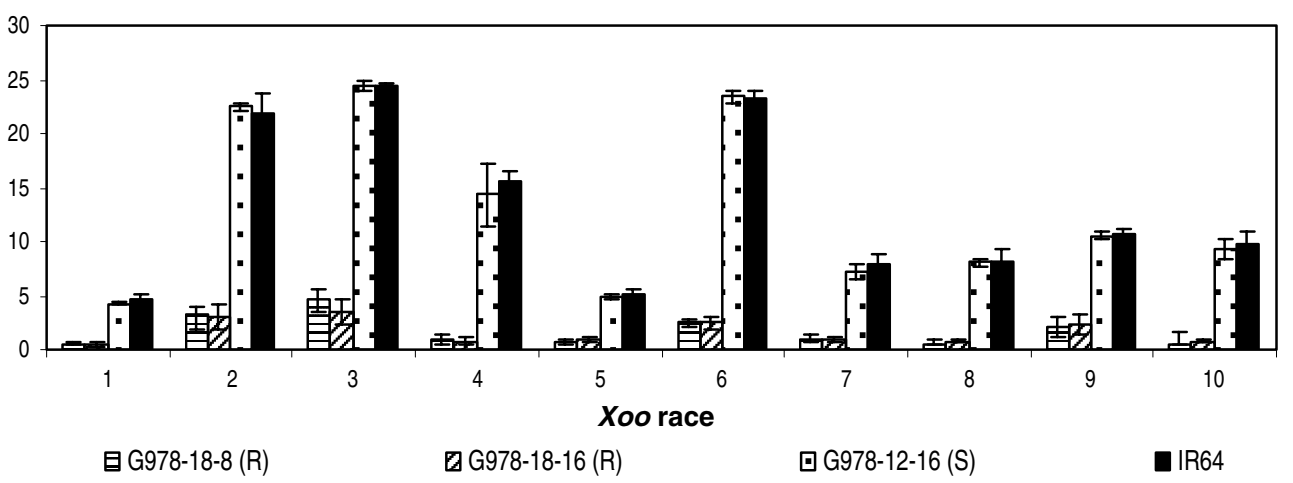

b

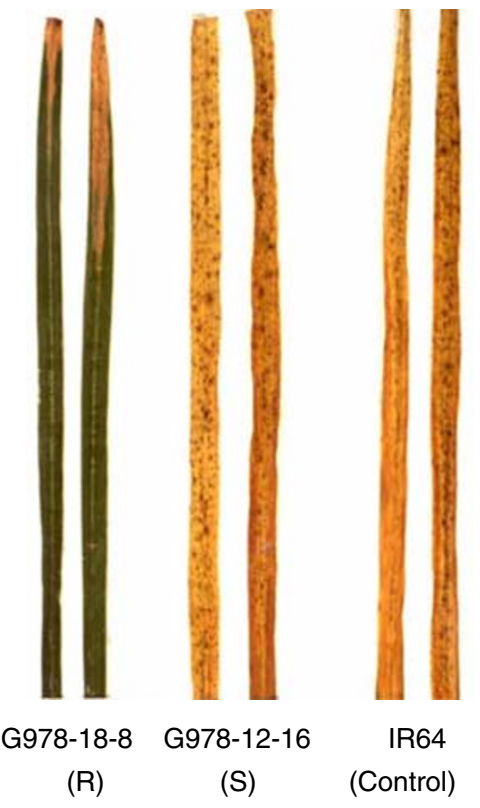

C
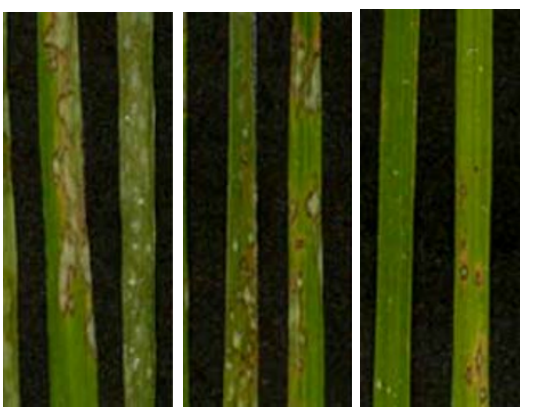

CO39

IR64

G978-18

(R)

Blast (Ca89)

Bacterial blight (PX087)

To determine the reaction of G978-18 to panicle blast, the mutant was grown to maturity under natural conditions in Cavinti, Laguna, Philippines, known to be a "hotspot" for blast. The two G978-18 mutant sister lines showed a four-fold reduction in disease compared to the susceptible sister line G978-12-16 and IR64 as measured by the disease severity index (Electronic Supplementary Material Fig. S1).

Thus, phenotypic characterization in greenhouse inoculations and field tests supported the conclusion that the G978-18 mutant has broad-spectrum resistance against both bacterial blight and blast. Furthermore, resistance to panicle blast was effective in the field, an important consideration for blast resistance.

Genetic analysis of resistance in G978

The inheritance of resistance in G978 was studied using $\mathrm{M}_{4}$ and $\mathrm{BC}_{1} \mathrm{~F}_{2}$ segregation data. Table 2 shows the segregation
Table 1 Mean Lesion Density and Percent Diseased Leaf Area (\% DLA) of IR64-Derived Mutant Lines at Seedling Stage Using Two Blast Isolates, PO6-6 and Ca89

\begin{tabular}{llllll}
\hline Line & \multicolumn{2}{l}{ PO6-6 $^{\mathrm{a}}$} & & \multicolumn{2}{c}{ Ca89 } \\
\cline { 2 - 3 } \cline { 5 - 6 } & $\begin{array}{l}\text { Lesion } \\
\text { density }^{\mathrm{b}}\end{array}$ & $\begin{array}{l}\% \\
\text { DLA }\end{array}$ & & $\begin{array}{l}\text { Lesion } \\
\text { density }\end{array}$ & $\begin{array}{c}\% \\
\text { DLA }\end{array}$ \\
\hline G978-18-8 & $2.44^{\mathrm{b}}$ & $5.62^{\mathrm{b}}$ & & $0.24^{\mathrm{b}}$ & $0.67^{\mathrm{b}}$ \\
G978-12-16 & $5.12^{\mathrm{a}}$ & $32.47^{\mathrm{a}}$ & & $2.92^{\mathrm{a}}$ & $14.30^{\mathrm{a}}$ \\
IR64 & $4.05^{\mathrm{a}}$ & $27.47^{\mathrm{a}}$ & & $3.84^{\mathrm{a}}$ & $17.90^{\mathrm{a}}$ \\
\hline
\end{tabular}

${ }^{\mathrm{a}}$ Inoculum concentration $=75$ spores $/ \mathrm{ml}$

${ }^{\mathrm{b}}$ Means followed by a common letter are not significantly different at the $5 \%$ level by LSD 


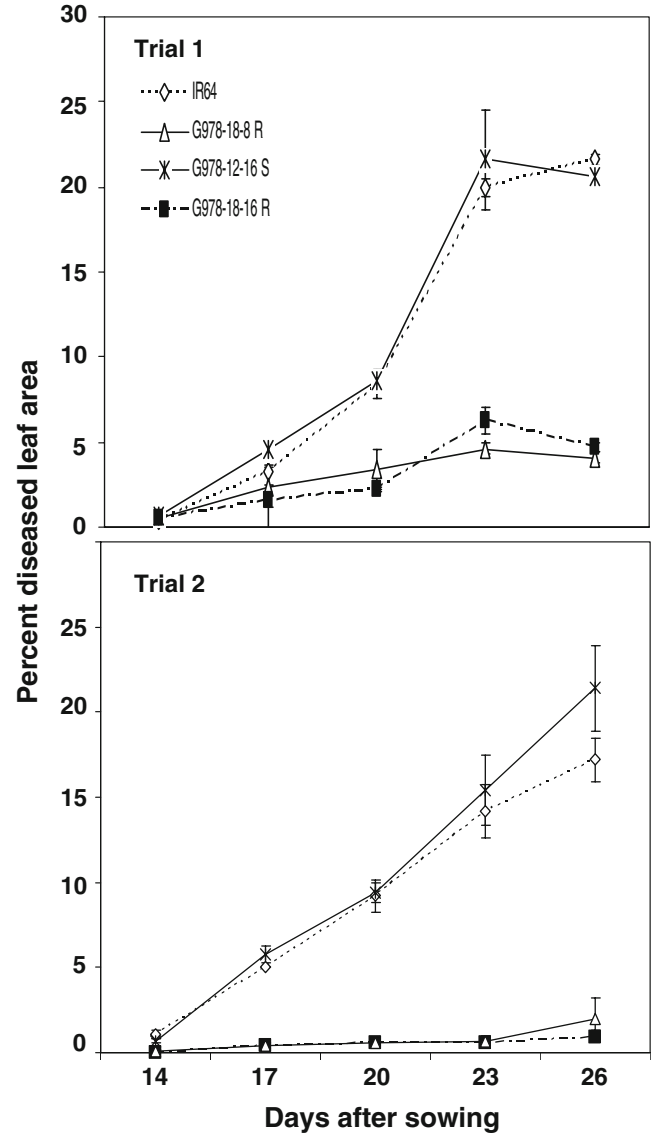

Fig. 2 Disease progress of leaf blast in two resistant G978-18 mutant lines compared to that in susceptible sister lines and IR64 in two independent field trials at IRRI blast nursery. Data points represent mean values of three replications. Error bars indicate \pm SE.

for $\mathrm{BB}$ resistance among progenies of six susceptible $\mathrm{M}_{3}$ plants. In each of the families, a 3 susceptible (S):1 resistant (R) ratio was observed when plants were inoculated with PXO87, suggesting that the mutation was conditioned by a single recessive gene. To confirm the inheritance pattern, we generated $\mathrm{BC}_{1} \mathrm{~F}_{2}$ progeny of G978 backcrossed to IR64. The ratio of S and R plants for G978-derived $F_{2}$ fitted the expected ratio of $3 \mathrm{~S}: 1 \mathrm{R}$, consistent with the segregation in the $\mathrm{M}_{4}$. The frequency distribution of lesion lengths in the $\mathrm{F}_{2}$ progeny after inoculation with PXO87 was bimodal (ESM Fig. S2). Agronomically, the mutant was significantly shorter than IR64 (ESM Fig. S3). The number of tillers of G978-18 was reduced though reduction was not statistically significant (ESM Table S1). The pleiotropic effect of the mutation in G978 was confirmed by the co-segregation between disease resistance phenotype and short stature in the $\mathrm{BC}_{1} \mathrm{~F}_{2}$ progeny.

Together, the results of $\mathrm{M}_{4}$ segregation and backcross analysis support the conclusion that the mutation in G97818 is controlled by a single, recessive gene. Allelism tests between the mutation in G978 and the previously reported gain-of-resistance genes ebrl and ebr3 (Campbell and Ronald 2005) were conducted. Under the conditions tested, the $e b r 1 \times \mathrm{G} 978 \mathrm{~F}_{1} \mathrm{~s}(n=60), e b r 3 \times \mathrm{G} 978 \mathrm{~F}_{1} \mathrm{~s}(n=59)$ and the CO39-derived ebr mutants were as susceptible to Xoo strain PXO99 as CO39 (data not shown). G978, on the other hand, showed enhanced resistance and had shorter lesions than the $F_{1} s$. These results suggest that the G978 mutation is non-allelic to either $e b r l$ or $e b r 3$. We designated the mutation in G978-18 as Bsdr1 for Broad-spectrum $d$ isease resistance because the mutation confers resistance to multiple strains for at least two pathogens tested.

Mapping of the $B s d r 1$ mutation

A total of $977 \mathrm{~F}_{2}$ progeny derived from the cross between G978-18 and Azucena were inoculated with PXO87. The frequency distribution for disease reaction to PXO87 is presented in Fig. 3a. Segregation of $F_{2}$ progeny fitted a $3 \mathrm{~S}: 1 \mathrm{R}$ ratio $\left(747 \mathrm{~S}: 230 \mathrm{R}, \chi^{2}=1.11, P=0.29\right)$, consistent with the $\mathrm{BC}_{1} \mathrm{~F}_{2}$ segregation (Table 2)

Table 2 Inheritance Pattern of Gain-Of-Resistance Phenotype in G978 $\mathrm{M}_{4}$ and Backcross Families

\begin{tabular}{|c|c|c|c|c|c|c|}
\hline \multirow[t]{2}{*}{ Category } & \multirow[t]{2}{*}{ Parent (S phenotype) } & \multirow[t]{2}{*}{ Number of progeny } & \multicolumn{2}{|c|}{ Observed segregation ratio } & \multirow[t]{2}{*}{$\chi^{2}$} & \multirow[t]{2}{*}{$P$ value } \\
\hline & & & Susceptible & Resistant $^{\mathrm{b}}$ & & \\
\hline \multirow[t]{7}{*}{$\mathrm{M}_{4}$ segregating family } & G978-12-2 & 20 & 15 & 5 & 0 & 1.0 \\
\hline & G978-12-4 & 20 & 17 & 3 & 1.07 & 0.30 \\
\hline & G978-12-5 & 20 & 12 & 8 & 2.40 & 0.12 \\
\hline & G978-12-6 & 20 & 16 & 4 & 0.27 & 0.61 \\
\hline & G978-12-7 & 19 & 15 & 4 & 0.16 & 0.69 \\
\hline & G978-12-8 & 20 & 12 & 8 & 2.40 & 0.12 \\
\hline & Pooled $\mathrm{M}_{4}$ families & 119 & 89 & 30 & 0.003 & 0.96 \\
\hline $\mathrm{BC}_{1} \mathrm{~F}_{2}$ & G978-18 × IR64 & 98 & 81 & 17 & 3.061 & 0.08 \\
\hline
\end{tabular}

${ }^{\text {a }} P$-value $\geq 0.05$ indicates non-significant deviation from the 3 susceptible: 1 resistance ratio based on Chi-square test

${ }^{\mathrm{b}}$ Expected segregation ratio is $3 \mathrm{~S}: 1 \mathrm{R}$ if character is controlled by a single, recessive gene 



Fig. 3 Mapping of enhanced resistance phenotype using $F_{2}$ progeny of G978-18 × Azucena. a Frequency distribution of lesion lengths $(\mathrm{cM})$ in $\mathrm{F}_{2}$ progeny inoculated with Xoo strain PXO87. b Five SSR markers (encircled in red) on chromosome 12 associated with BB resistance phenotype (lesion length). The numbers on the left indicate genetic distance (cM) in Kosambi units. Single-marker analysis was

To determine the chromosomal location of the G978-18 mutation, 73 polymorphic SSR markers from 12 chromosomes were used to genotype 200 progeny representing the phenotypic extremes of the $F_{2}$ population. Six markers near the centromere on chromosome 12 showed highly significant association with the resistance phenotype based on the $P$ value. Some SSR markers from chromosomes 3 and 4 also showed association with resistance but their effects were much smaller than those of the markers on chromosome 12 (ESM Table S2). They likely resulted from segregation of QTL effects between IR64 and Azucena (Ramalingam et al. 2003). done using MAPManager QTX (Meer et al. 2002) c QTL region defined by interval mapping with high confidence (based on bootstrap and $L O D=31.8$ ) using mean lesion length. LOD score was based on 500 permutations. d QTL mapping using ratio of mean lesion length over plant height as trait values tested for association with marker loci used ( $\mathrm{LOD}=28.2)$.

Regression analysis of additional simple sequence repeat (SSR) markers on chromosome 12 showed RM2529, RM101, RM1036 and RM2935 to be highly associated with the resistance phenotype, with logarithm of odds (LOD) scores of 26.6, 25.9, 25.1, and 23.9, respectively, accounting for $42-46 \%$ of the variance (ESM Table S3). However, RM1047 was considered not informative by marker regression function of MAPManager QTX, possibly because of segregation distortion in the progeny used. Thus, interval mapping was used to locate the mutation by analyzing the quantitative effects of the mutation (MAPManager QTX; Meer et al. 2002). The map positions of the 
QTLs are shown in Fig. 3b. A QTL region on chromosome 12 was defined with high confidence based on bootstrap value. The five SSR markers detected previously by singlemarker regression analysis were within this QTL region. It had a LOD of 31.8 which was seven times higher than the LOD score threshold established based on 500 permutations (Fig. 3c). Because lesion length measurements might be influenced by plant height/leaf length, we used ratios of lesion length to plant height as trait values to test for association with marker loci. The analysis showed the same markers to be significantly associated with resistance phenotype ( $\mathrm{LOD}=28.2$, Fig. $3 \mathrm{~d}$ ). Thus, several mapping approaches placed the mutation within $3.8 \mathrm{Mb}$ between positions 7.4 and $11.2 \mathrm{Mb}$ (based on TIGR version 5.0 of the rice pseudomolecules).

Candidate genes identified from differentially expressed genes in chromosome 12

It has been shown that genome-wide expression profiling could reveal candidate genes responsible for mutant phenotypes, assuming that the mutation affects the expression of the target gene (Dybbs et al. 2005). Since G978 was mutagenized by gamma ray, we expected that the expression of the mutated gene could be down-regulated or completely abolished. We used gene expression data of G978 and its wild-type parent IR64 (R. Mauleon et al, manuscript in preparation) to identify genes that were differentially expressed at 24 and $48 \mathrm{~h}$ after inoculation. By setting a $\log _{2}$ ratio of 0.5 threshold for difference in expression values between G978 and IR64 at either time point, we identified 40 genes on chromosome 12 (ESM Table S4).

Based on the criterion of low expression at two time points, seven genes were selected. Among them, three genes were located inside or relatively close to the mapped locus. These included AK102429, annotated as coding for a U-box and Arm-repeated protein, AK111521, RNA-binding protein, and AK064188, unknown protein. Based on RT-PCR, we detected transcript for AK111521 with no indication of down regulation (Fig. 4). For AK064188, we were able to detect a faint fragment with cDNA of G978. In contrast, no transcript was detected for AK102429 at all conditions tested, suggesting that the AK102429 gene was disrupted. AK102429 is located within the mapped region between positions 7.4 and 11.2 $\mathrm{Mb}$ whereas AK064188 was located outside the mapped region. Southern blot analysis of segregating $\mathrm{BC}_{2} \mathrm{~F}_{2}$ progeny of G978 $\times$ IR64 further confirmed that the polymorphism in AK102429 co-segregated with gainof-resistance phenotype (Fig. 5b). Together, these results suggested that AK102429 is a promising candidate gene for the mutation.

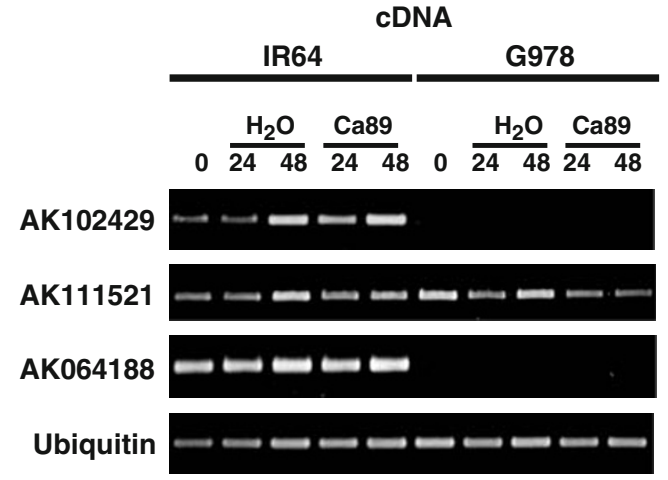

Fig. 4 Expression analysis of three candidate genes AK102429, AK11521, and AK064188 on chromosome 12. RT-PCR was performed by gene-specific primer pairs as described in the "Methods" section. Ubiquitin was used as a control.

\section{Discussion}

We have genetically defined a mutation that shows broadspectrum resistance to multiple races of blast and $\mathrm{BB}$ pathogens. This study shows that mutations for quantitative traits can be isolated from mutant lines provided that detailed phenotyping is done in replicated tests. Unlike major R genes, the resistance is quantitative. In G978-18, the reduction in lesion length to $\mathrm{BB}$ is consistent across multiple races of the pathogen. The degree of resistance, however, varied between experiments and genetic backgrounds. Typical of segregation of quantitative resistance, lesion length reduction varied among progeny derived from G978 $\times$ Azucena cross. Blast resistance in G978-18 was manifested as a reduction in lesion number rather than prevention of lesion development.

To evaluate broad-spectrum resistance under realistic agronomic setting, it is important to have mutants without severe pleiotropic effects. The $B s d r 1$ mutation renders the plant shorter with fewer tillers, but not severely abnormal as is common with many gain-of-resistance mutants in Arabidopsis (Shirano et al. 2002; Vogel and Somerville 2000). The minor pleiotropic effect makes this mutant a good candidate for more detailed phenotypic characterization. We were able to grow G978 to maturity under field conditions to determine that the $B s d r 1$ mutation conferred resistance to panicle blast. This result helps clarify the uncertainty of whether genes controlling leaf blast resistance are effective against panicle blast. Under our experimental conditions, resistance to leaf and neck blast was expressed in the field, indicating that resistance in different tissue types can be conferred by the same genetic mechanism. Identification of a genetic factor responsible for reducing panicle blast is particularly valuable as many varieties tend to have strong resistance to leaf blast yet succumb to panicle blast.

The gain-of-resistance mutation does not fall into the common categories of lesion mimics mutants which 
Fig. 5 Co-segregation of resistance phenotype and AK102429 gene in G978 $\times$ IR64 $\mathrm{BC}_{2} \mathrm{~F}_{2}$ progeny. a Bam $\mathrm{HI}$ restriction sites in relation to the gene structure of AK102429 on chromosome 12 and the position of probe used for Southern blot. b Southern blot analysis of G978 $\times$ IR64 $\mathrm{BC}_{2} \mathrm{~F}_{2}$ progeny (17 resistant and seven susceptible) using AK102429 gene probe defined by the primer pair: UboxMFTCCGTTCCACTT

GATCACAA, UboxMRGCCGAACCATTGTCACTT TT. Resistance to bacterial blight was measured as lesion length (cM) and indicated at the bottom of each lane. All resistant lines are homozygous for the mutant allele, whereas the susceptible lines include both heterozygous and homozygous genotypes. a

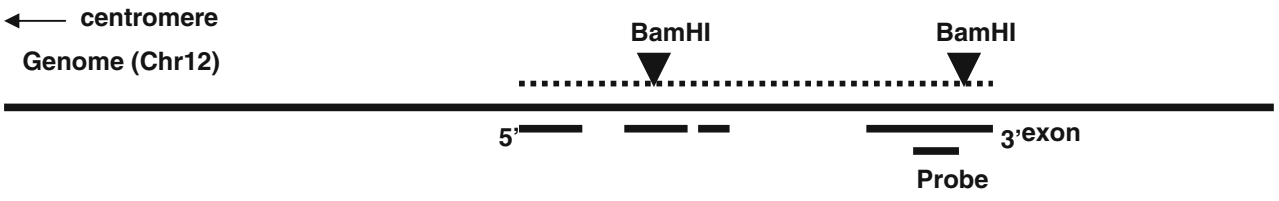

b


involve initiation or propagation of cell death (Lorrain et al. 2003). At the macroscopic level, we did not observe leaf spots under the greenhouse conditions tested. Thus, the resistance does not appear to require cell death as a precondition for restricting disease spread. However, when G978-18 was grown to maturity in the field, we observed darkening of the leaf sheath and of the panicle at heading. Whether it is a result of cell death or accumulation of pigment under a relatively more stressful environment needs further investigation. Thus, we cannot rule out the possibility that lesion mimics could be formed under stressed or growth-limiting conditions. Campbell and Ronald (2005) reported three mutations ebrl, ebr2, and $e b r 3$ with enhanced resistance to blast. The ebrl and ebr3 mutants also showed enhanced resistance to bacterial blight. In addition, ebr3 showed lesion mimic phenotype when challenged by the pathogens. We tested for allelism between the G978 and the ebr 1 and $e b r 3$ mutations. In our test, ebrl, ebr3, and their $\mathrm{F}_{1} \mathrm{~s}$ with $\mathrm{G} 978$ were all as susceptible to PXO99 as CO39. Based on allelism tests and the phenotypic descriptions of the ebr mutants, $B s d r 1$ appears distinct from the ebrl, ebr2, and ebr3 mutations.

Using a genetic cross with Azucena, we mapped $B s d r 1$ onto a $30.8 \mathrm{cM}$ region on chromosome 12 . The LOD score is highly significant $(P<0.0001)$ indicating a major phenotypic effect of $B s d r 1$. Based on the current version of the pseudomolecule, the physical distance defined by the flanking SSR markers is about $3.8 \mathrm{Mb}$, which is considerably less than that predicted by the average physical distance of $300 \mathrm{~kb}$ per cM (Arumuganathan and Earle 1991;
Harushima et al. 1998). The large genetic distance could be caused by a lack of recombination in the region, which may hinder positional cloning based on fine mapping.

To overcome the potential problem of limited recombination around the mutation locus, we applied expression analysis to short list candidate genes for more detailed investigation. The physical boundaries defined by the genetic markers are approximate due to expected differences in the japonica versus indica genomes. Thus, without additional filtering, it would be virtually impossible to extract promising candidate genes within the $3.8-\mathrm{Mb}$ region. We reasoned that if the mutation had caused a down expression of the mutated gene, it could be detected by examining the expression of a subset of genes in the chromosomal region delimited by mapping (Fig. 3). Since the location of the mutation is known, we took a liberal approach to identify candidate genes in the target region to avoid making a false negative declaration (i.e., rather committing a Type I than Type II error). In total, 40 down-expressed genes (mutant vs. wild type) were found from the genotypic contrasts. Of these, the putative U-box gene showed null transcript and co-localized within the 3.8 $\mathrm{Mb}$ defined by QTL mapping. Co-segregation analysis further supported the hypothesis that mutation in this U-box gene is causally related to the phenotype.

Although the causal relationship between the U-box gene and mutant phenotype remains to be verified, this candidate gene holds considerable promise based on its predicted biological functions. Many U-Box genes function in the ubiquitination protein degradation pathway that 
regulates cellular function through control of protein quality and turnovers (Devoto et al. 2003b; Moon et al. 2004). One such U-Box gene in rice is encoded by the Spll1 locus where a mutation gives enhanced resistance to blast and blight (Zeng et al. 2002, 2004). Spll1 encodes an E3 ubiquitin ligase that functions as a negative regulator of programmed cell death. It appears that mutation at Spl11 results in a deregulation of defense response leading to cell death and an elevated level of resistance. Expression of resistance and the degree of lesion mimics are correlated in spll1 mutant. Although we cannot conclude that $B s d r 1$ mutant is free of lesion mimics under all conditions, resistance can be observed at stages with no apparent lesion mimics. Thus, resistance conferred by $B s d r 1$ seems to be temporally and spatially uncoupled from cell death. The $B s d r 1$ mutation identified in this study provides an entry point to identify critical steps in known or yet to be discovered defense pathways.

In conclusion, through systematic screening, we have identified a rare mutant with gain-of-resistance to blast and bacterial blight without serious pleiotropic effects. So far, enhanced resistance against multiple diseases in rice has been reported mostly in lesion mimic mutants (Mizobuchi et al. 2002; Wu et al. 2008), thus, determining how a mutation with no pronounced cell death (lesion mimics) can mediate multiple disease resistance is of practical interest. By combining mapping and gene expression profiling, we narrowed down to a candidate gene responsible for the mutation. By examining transcripts rather than genomic DNA, this approach can be generally applicable to detecting mutations caused by deletions as well as other physical changes (e.g., point mutations or chromosomal rearrangements) that abolish gene expression. The power of this approach can be increased considerably through the use of the 44-K oligoarray (Agilent) or other chips with nearcomplete genome coverage.

\section{Methods}

Screening IR64 mutants for gain-of resistance

Gamma-ray mutagenesis was conducted at the International Atomic Energy Agency, Austria, whereas the mutagenized seeds were planted in the greenhouse at the International Rice Research Institute (IRRI), Philippines. Details of the production and maintenance of the IR64 mutants are described in Wu et al. (2005).

Because of the ease of using lesion length as a quantitative trait, our initial screen for gain-of-resistance mutants was based on reaction to bacterial blight. Ten plants per $\mathrm{M}_{2}$ family were inoculated at 45 days after sowing (das) with PXO87, a virulent Xoo isolate, by leaf- clipping method (Kauffman et al. 1973). Progeny from putative gain-of-resistance mutants and "sister" $\mathrm{M}_{2}$ plants (a total of six $\mathrm{M}_{2}$ lines per $\mathrm{M}_{1}$ ) were inoculated with PXO87 to confirm the mutation. Selected BB gain-ofresistance mutants were later tested for blast resistance as described below. From screening approximately 10,000 $\mathrm{M}_{2}$ families, two gain-of-resistance mutants were identified but only analysis of G978 was considered in this study.

\section{Characterization of resistance to bacterial blight}

The gain-of-resistance mutant lines G978-18-8 and G97818-16, together with susceptible wild-type sister line G978$12-16$, were tested against representative strains of $10 \mathrm{Xoo}$ races from the Philippines in the greenhouse. The experiment was done in three replications using a split-plot design (four plants per line per isolate per replicate) using IR64 as control. Plants were sown in pairs in $31 \times 23 \mathrm{~cm}$ plastic containers. The upper and lower leaves of three main tillers of each plant were clip-inoculated at 45 das. Lesion lengths were scored 14 days after inoculation. The representative strains of the ten races were PXO61 (race 1), PXO86 (race 2), PXO340 (race 3), PXO71 (race 4), PXO112 (race 5), PXO99 (race 6), PXO145 (race7), PXO280 (race 8), PXO339 (race 9), and PXO341 (race 10).

\section{Characterization of resistance to blast}

The BB resistant G978-18-8 line was tested against blast fungal isolates $\mathrm{Ca} 89$ and PO6-6 from the Philippines at inoculum concentrations of $25 \times 10^{4}$ conidia/ml and $75 \times 10^{4}$ conidia/ml. The susceptible sister line G978-12-16 and IR64 were included as controls. A randomized complete block design with three replicates was used for each isolate and inoculum concentration. Fifteen seeds per line per replicate were sown in $35 \times 28 \times 11-\mathrm{cm}^{3}$ plastic trays and grown in the greenhouse. Fourteen-day-old seedlings were sprayed with $100 \mathrm{ml}$ of the spore suspension for each tray. Plants were incubated in a chamber with $100 \%$ relative humidity for $24 \mathrm{~h}$ at $26^{\circ} \mathrm{C}$ and then transferred to an air-conditioned glasshouse room at $25-28^{\circ} \mathrm{C}$. The seedlings were misted with water four times a day at daytime until scoring. Lesion density and percent diseased leaf area (DLA) were measured as described by Roumen (1993) and Notteghem et al. (1981) were scored 5-7 days after inoculation (dai).

Field evaluation under natural infection

Two G978-18 lines, susceptible sister line G978-12-16, IR64, and CO39 (susceptible check) were exposed to natural pathogen population in the blast nursery at IRRI, Philippines during the wet seasons of 2001 and 2003. Fifty seeds per line were planted in half row in a $10 \times 1.2-\mathrm{m}$ 
concrete bed. Five replicates and a randomized complete block design were used. The plot was surrounded by spreader rows of susceptible cultivars IR50 and IR72 to multiply the natural inocula. Percent DLA and lesion number was recorded at $14,17,20,23$, and 26 das.

To evaluate the reaction of the mutant against panicle blast, the same lines tested in the IRRI blast nursery were grown to maturity in a farmer's field in Cavinti, Laguna, Philippines (a non-irrigated, upland rice system). A main plot of $4 \times 21 \mathrm{~m}^{2}$ was established and divided into three subplots to serve as three replicates. Each subplot $\left(4 \times 8 \mathrm{~m}^{2}\right)$ was divided into four small plots. The five test materials (including the control CO39) were planted in rows (22 hills per row per line with three seeds per hill) in each of the small plots in a completely randomized design. Each of the small plots was surrounded with spreader rows consisting of IR50 and IR72. Disease severity at reproductive stage was assessed by scoring five panicles per hill and ten hills per line per small plot per replicate using a $0-5$ scale. Disease severity index $(0-100)$ was computed based on a modified formula of Hildebrand et al. (2001) where $n_{i}$ is the number of panicles for ten hills in disease rating $i$, for $i=0$ to 5. Data were analyzed with ANOVA in SAS Program, VERSION 6.12 (SAS Institute, 1989).

\section{Genetic analysis and mapping}

Inheritance of the mutation in G978 was inferred by observing the segregation of reaction to Xoo strain PXO87 among $\mathrm{M}_{4}$ progeny of six susceptible $\mathrm{M}_{3}$ plants. To further confirm the inheritance, the mutant, G978-18 was backcrossed to IR64 and the $\mathrm{BC}_{1} \mathrm{~F}_{2}(n=98)$ inoculated with PXO87 for segregation analysis. To test for allelism to previously reported gain-of-resistance mutations $e b r l$ and ebr3 which also confer resistance to both $\mathrm{BB}$ and blast (Campbell and Ronald 2005), a resistant G978 line was crossed to the two mutants. The $\mathrm{F}_{1} \mathrm{~s}$, parents, and wild-type $\mathrm{CO} 39$ and IR64 were inoculated with Xoo strain PXO99 at 45 das, and lesion lengths were measured at 17 dai. Allelic test between the G978 mutation and ebr2, which showed enhanced resistance only to blast (Campbell and Ronald 2005), was not done.

To locate the G978 mutation, we crossed G978-18 mutant with Azucena, a traditional japonica with a high level of polymorphism relative to IR64. About 1,000 $\mathrm{F}_{2}$ plants were advanced to $F_{3}$. The $F_{2}$ population was phenotyped for $\mathrm{BB}$ reaction using isolates PXO61 and PXO87. Because the resistance phenotype is quantitative, $\mathrm{F}_{3}$ families were evaluated to confirm $\mathrm{F}_{2}$ phenotypes. Based on the $F_{2}$ and $F_{3}$ phenotypes, $60 F_{2}$ individuals were classified as highly resistant (R), 60 as highly susceptible (S) and 80 as moderately susceptible. These $200 \mathrm{~F}_{2}$ plants were used for genotyping to map the mutation.
DNA extraction and microsatellite analysis

DNA from individual G978-18 $\times$ Azucena $F_{2}$ plants selected for mapping was isolated from fresh leaves using the CTAB method (Murray and Thompson, 1980). A total of 73 Rice Microsatellite (RM) primer pairs (Research Genetics, Inc., Huntsville, Alabama) were used to genotype the selected $200 \mathrm{~F}_{2}$ progeny. Genomic DNA was used as a template for PCR amplification with cycling conditions of $94^{\circ} \mathrm{C}$ for $5 \mathrm{~min}$ as hot start; 35 cycles of $94^{\circ} \mathrm{C}$ at $1 \mathrm{~min}$ for denaturation; $55-60^{\circ} \mathrm{C}$ annealing for $1 \mathrm{~min} ; 72^{\circ} \mathrm{C}$ extension for $2 \mathrm{~min}$; and a $7 \mathrm{~min}$ final extension at $72^{\circ} \mathrm{C}$. The PCR products were run on a $40-\mathrm{cm}$ long $4 \%$ denaturing polyacrylamide gels for $1.5 \mathrm{~h}$ at 80 constant watts and silver stained according to the manufacturer's instructions (Promega, USA).

The resulting bands were visually scored by comparing them to the bands of the resistant (G978-18) and susceptible (Azucena) parents. Linkage relationships were analyzed by Quantitative Trait Loci (QTL)/Simple Interval Mapping and Marker regression analysis with the MAPManager program (Meer et al. 2002) using the Kosambi mapping function (Kosambi 1944).

Microarray analysis to identify differentially expressed genes in target region

Gene expression profiles of 21-day-old G978 at $24 \mathrm{~h}$ and $48 \mathrm{~h}$ after blast inoculation using isolate Ca89 $\left(100 \times 10^{4}\right.$ conidia/ml) were obtained using the Agilent Technologies $22 \mathrm{~K}$ rice oligoarray, which represents about $50 \%$ of the expressed genes in rice. Total RNA was isolated from whole plants of G978 and IR64 in each sampled time point using Trizol (Life Technologies Inc., Gaithersburg, MD, USA) protocol. For each array, blast-inoculated and watertreated RNA samples from the same variety and same sampling time point were hybridized and compared (G978 inoculated vs. water, IR64 inoculated vs. water) with three biological replicates per experiment. The experiments were conducted at the National Institute of Agrobiological Sciences, Tsukuba, Japan.

To identify differentially expressed genes in the chromosomal region where the mutation was mapped, we used independent $t$ tests (Pan 2002). We adopted a less stringent test as we were primarily interested in finding candidates in the target region and less concerned with having false positives. The independent $t$ test for each experiment was able to detect genes that were significantly expressed even with low expression ratios because unknown error variance components were estimated based on a gene-specific variance for each gene. For the independent $t$ tests, the significant differentially expressed genes (DEGs) were first determined for each rice entry-treatment comparison (e.g., 
G978 inoculated vs. water, three bioreps) using one-class $t$ test for each gene. The mean of gene expression $\left(\log _{2}\right.$ ratio) for three biological replicates was tested for significant difference against zero (no difference in gene expression between samples compared). Significant DEGs between the resistant and susceptible entries were then tested using twoclass $t$ test, with G978 as class A and IR64 as class B, using three replicates. Each $t$ test generated a list of significant and non-significant genes. At each time point, from the DEGs set, the subsets of genes that were significantly differentially induced (DI genes) by blast inoculation in G978 were determined by the Boolean join. All $t$ tests were done using significance $\alpha=0.01$ with adjusted Bonferroni correction, and $p$ values based on 1,000 times permutation, as implemented by TIGR Multiple Experiment Viewer v 3.1, available at http://www.tm4.org/.

\section{RT-PCR and Southern blot analyses}

RT-PCR was used for RNA expression analysis of the three down-regulated genes (AK102429, AK111521, and AK064188) from microarray result using the gain-ofresistance mutant and the wild-type IR64 at different time points after infection. A resistant $\mathrm{BC}_{1} \mathrm{~F}_{3}$ G978 line was grown together with IR64 in the greenhouse. Plants were inoculated with blast isolate Ca89 and with $\mathrm{H}_{2} \mathrm{O}$ as control at 17 das. Leaves were collected at 0,24 , and $48 \mathrm{~h}$ after inoculation, same time points for microarray expression analysis. Total RNA was isolated by TRIZOL Reagent (Invitrogen). After DNase treatment by deoxyribonuclease I amplification grade (Invitrogen), first-strand cDNA was synthesized with the Superscript ${ }^{\mathrm{TM}}$ II Reverse Transcriptase (Invitrogen). TAKARA Ex Taq (TAKARA Bio Inc.) was used for PCR. The PCR condition used for these genes was $95^{\circ} \mathrm{C}$ for $30 \mathrm{~s}, 58^{\circ} \mathrm{C}$ for $30 \mathrm{~s}, 72^{\circ} \mathrm{C}$ for $60 \mathrm{~s}$ for 32 cycles. UboxMF-TCCGTTCCACTTGATCACAA, UboxMRGCCGAACCATTGTCACTTTT for AK102429, M10FCTCAAGCACAGGGAGAGGAG，M10R-CAAGGAGC CTGGACAAGAAG for AK111521, and C04(144)F-CAG AGGCAGAGGCTTTTGAG, C04(413)R-GGACGGT CAAATGCAAGAAT for AK064188.

Southern blot analysis was used to determine cosegregation of $\mathrm{BB}$ resistance (using PXO87) and candidate gene AK102429 in the $\mathrm{BC}_{2} \mathrm{~F}_{2}$ of $\mathrm{G} 978$ and IR64. AK102429 gene probe was defined by the primer pair: UboxMF-TCCGTTCCACTTGATCACAA, UboxMRGCCGAACCATTGTCACTTTT. DNA from selected susceptible $(n=7)$ and resistant $(n=17) \mathrm{BC}_{2} \mathrm{~F}_{2}$ was extracted as described above. Total DNA $(10 \mu \mathrm{g})$ was digested by BamHI (Amersham Biosciences), and the digested DNA was resolved by electrophoresis using $0.9 \%$ agarose gel. DNA was transferred to Hybond $\mathrm{N}+$ nylon membrane under alkaline condition. ECL Direct Nucleic Acid Labeling and
Detection Systems (Amersham Biosciences) were used for detection of hybridization signal.

Acknowledgments We thank P. Donini, F. Zapata, and R. Afza of International Atomic Energy Agency, Vienna, for conducting gammaray mutagenesis from which the mutants understudied were identified. This work is supported in part by Swiss Agency for Development and Cooperation (SDC).

\section{References}

Anderson JP, Thatcher L, Singh K. Plant defence responses: conservation between models and crops. Func Plant Biol. 2005;32:21-34.

Arase S, Zhao C-M, Akimitsu K, Yamamoto M, Ichii M. A recessive lesion mimic mutant of rice with elevated resistance to fungal pathogens. J Gen Plant Pathol. 2000;66:109-16.

Arumuganathan K, Earle ED. Nuclear DNA content of some important plant species. Plant Mol Biol Rep. 1991;9:229-41.

Buschges R, Holricher K, Panstruga R, Simons G, Wolter M, Frijters A, et al. The barley Mlo gene: a novel control element of plant pathogen resistance. Cell. 1997;88:695-705.

Campbell MA, Ronald PC. Characterization of four rice mutants with alteration in the defense response pathway. Mol Plant Pathol. 2005;6:11-21.

Devoto A, Piffanelli P, Nilsson I, Wallin E, Panstruga R, von Heijne G, et al. Topology, subcellular localization, and sequence diversity of the Mlo family in plants. J Biol Chem. 1999;274:34993-5004.

Devoto A, Hartmann HA, Piffanelli P, Elliot C, Simmons C, Taramino G, et al. Molecular phylogeny and evolution of the plant-specific seven transmembrane MLO family. J Mol Evol. 2003a;56:77-88.

Devoto A, Muskett PR, Shirasu K. Role of ubiquitination in the regulation of plant defence against pathogens. Curr Opin Plant Biol. 2003b;6:307-11.

Dybbs M, Ngai J, Kaplan JM. Using microarrays to facilitate positional cloning:Identification of Tomosyn as an inhibitor of neurosecretion. PLoS Genet. 2005;1:e2.

Faris J, Li WL, Liu DJ, Chen PD, Gill BS. Candidate gene analysis of quantitative disease resistance in wheat. Theor Appl Genet. 1999;98:219-25.

Feys BJ, Parker JE. Interplay of signaling pathways in plant disease resistance. Trends Genet. 2000;16:449-55.

Freialdenhoven A, Peterhansel C, Kurth J, Kreuzaler F, Schulze-Lefert $P$. Identification of genes required for the function of non-racespecific mlo resistance to powdery mildew in barley. Plant Cell. 1996;8:5-14.

Frye CA, Innes RW. An Arabidopsis mutant with enhanced resistance to powdery mildew. The Plant Cell. 1998;10:947-56.

Frye CA, Tang D, Innes RW. Negative regulation of defenses response in plants by a conserved MAPKK kinase. Proc Nat Acad Sci USA. 2001;98:784-6.

Hammond-Kosack KE, Jones JDG. Resistance gene-dependent plant defense responses. The Plant Cell. 1996;8:1773-91.

Harushima Y, Yano M, Shomura A, Sato M, Shimano T, Kuboki Y, et al. A high-density rice genetic linkage map with 2275 markers using a single F2 population. Genetics. 1998;148:479-94.

Hildebrand PD, McRae KB, Lu X. Factors affecting flower infection and disease severity of lowbush blueberry by Botrytis cinerea. Can J Plant Pathol. 2001;23:364-70.

Kauffman HE, Reddy APK, Hsiek SPV, Marca SD. An improved technique for evaluating resistance of race varieties to Xanthomonas oryzae. Plant Dis Rep. 1973;57:537-41. 
Keen NT. Gene-for-gene complementarity in plant-pathogen interactions. Annu Rev Genet. 1990;24:444-63.

Kosambi DD. The estimation of map distances from recombination values. Ann Eugen. 1944;12:172-5.

Lorrain S, Vailleau F, Balague C, Roby D. Lesion mimic mutants: keys for deciphering cell death and defense pathways in plants? Trends Plant Sci. 2003;8:263-71.

Liu B, Zhang S, Zhu X, Yang Q, Wu S, Mei M, et al. Candidate defense genes as predictors of quantitative blast resistance in rice. Mol Plant-Microbe Interact. 2004;17:1146-52.

Lu G, Jantasuriyarat C, Zhou B, Wang G-L. Isolation and characterization of novel defense response genes involved in compatible and incompatible interactions between rice and Magnaporthe grisea. Theor Appl Genet. 2004;108:525-34.

Martin GB. Functional analysis of resistance genes and their own downstream effectors. Curr Opin Plant Biol. 1999;2:273-9.

Meer JM, Manly KF, Cudmore RH Jr. Map Manager QTXb14. Roswell Park Cancer Institute. 2002

Mizobuchi R, Hirabayashi H, Kaji R, Nishizawa Y, Satoh H, Ogawa $\mathrm{T}$, et al. Differential expression of disease resistance in rice lesion-mimic mutants. Plant Cell Rep. 2002;21:390-6.

Moon J, Parry G, Estelle M. The ubiquitin-proteoasome pathway and plant development. The Plant Cell. 2004;16:3181-95.

Notteghem JL, Chatel M, Dechanet R. In: Symposium sur la resistance du riz a la pyriculariose. Montpellier, France. IRATGERDAT 1981. pp 313-330.

Pan W. A comparative review of statistical methods for discovering differentially expressed genes in replicated microarray experiments. Bioinformatics. 2002;18(4):546-54.

Peterhansel C, Freialdenhoven A, Kurth J, Kolsch R, Schulze Lefert P. Interaction analyses of genes required for resistance responses to powdery mildew in barley reveal distinct pathways leading to leaf cell death. The Plant Cell. 1997;9:1397-409.

Ramalingam J, Vera Cruz CM, Kukreja K, Chittoor JM, Wu JL, Lee $\mathrm{SW}$, et al. Candidate resistance genes from rice, barley, and maize and their association with qualitative and quantitative resistance in rice. Mol Plant-Microbe Interact. 2003;6:14-24.

Roumen EC. Selection for partial resistance in rice to rice blast. Durability of Disease Resistance. Norwell: Kluwer; 1993. p. 195-200.

Shirano Y, Kachroo P, Shah J, Klessig D. A gain-of-function mutation in an Arabidopsis Toll Interleukin 1 receptor-nucleotide binding site-leucine-rich repeat type $\mathrm{R}$ gene triggers defense responses and results in enhanced disease resistance. The Plant Cell. 2002;4:3149-62.

Takahashi A, Kawasaki T, Henmi K, Shii K, Kodama O, Satoh K, et al. Lesion mimic mutants of rice with alterations in early signaling events of defense. Plant J. 1999;17:535-45.

Thatcher L, Anderson J, Singh K. Plant defence responses: what we learnt from Arabidopsis? Functional Plant Biol. 2005;32:1-19.

Vogel J, Somerville S. Isolation and characterization of powdery mildew-resistant Arabidopsis mutants. Proc Natl Acad Sci USA. 2000;97:1897-902.

Wang GL, Wu C, Zeng L, He C, Baraoidan M, de Assis Goes da Silva $\mathrm{F}$, et al. Isolation and characterization of rice mutants compromised in Xa21-mediated resistance to X. oryzae pv. oryzae. Theor Appl Genet. 2004;108:379-84.

Wen N, Chu Z, Wang S. Three types of defense-responsive genes are involved in resistance to bacterial blight and fungal blast diseases in rice. Mol Gen Genomics. 2003;269:331-9.

Wu C, Bordeos A, Madamba MRS, Baraoidan M, Ramos M, Wang GL, et al. Rice lesion mimic mutants with enhanced resistance to diseases. Mol Genet Genomics. 2008;279:605-19.

Wu J, Wu C, Lei C, Baraoidan M, Bordeos A, Madamba RS, et al. Chemical- and irradiation-induced mutants of indica rice IR64 for forward and reverse genetics. Plant Mol Biol. 2005;59:8597.

Yin Z, Chen J, Zeng L, Goh M, Leung H, Khush GS, et al. Characterizing rice lesion mimic mutants and identifying a mutant with broad-spectrum resistance to rice blast and bacterial blight. Mol Plant-Microbe Interact. 2000;13:869-76.

Yu I, Fengler K, Clough S, Bent A. Identification of Arabidopsis mutants exhibiting an altered hypersensitive response in genefor-gene disease resistance. Mol Plant-Microbe Interact. 2000;13:277-86.

Zeng L, Yin Z, Chen J, Leung H, Wang GL. Fine genetic mapping and physical delimitation of the lesion mimic gene Spl11 to a $160-\mathrm{kb}$ DNA segment of the rice genome. Mol Genet Genomics. 2002;268:253-61.

Zeng L, Qu S, Bordeos A, Yang C, Baraoidan M, Yan H, et al. Spl11, a negative regulator of plant cell death and defense, encodes a UBox/ARM repeat protein endowed with E3 ubiquitin ligase activity. The Plant Cell. 2004;16:2795-808. 